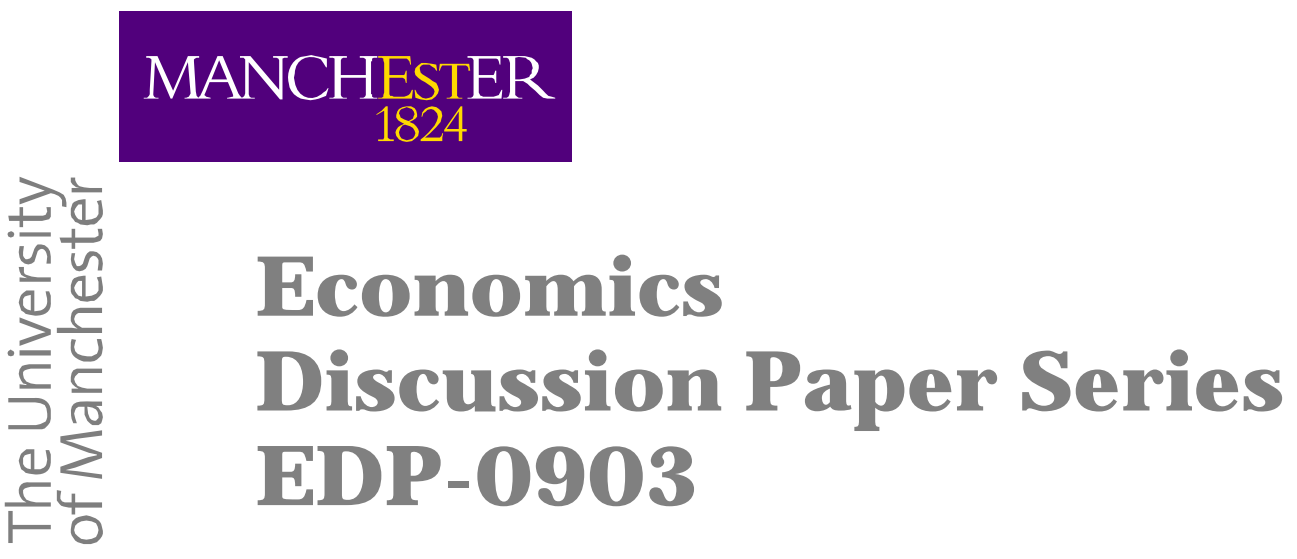

\title{
Conspicuous consumption, inconspicuous leisure
}

\author{
Kenneth Arrow \\ Partha Dasgupta
}

February 2009

Economics

School of Social Sciences

The University of Manchester

Manchester M13 9PL 
Forthcoming: Economic Journal

\title{
Conspicuous Consumption, Inconspicuous Leisure
}

\author{
by
}

Kenneth Arrow* and Partha Dasgupta**

First Version: June 2007

Present Version: February 2009

* Department of Economics, Stanford University. E-mail <arrow@ stanford.edu>

** Faculty of Economics, University of Cambridge; and Sustainable Consumption Institute, University of Manchester. E-mail <partha.dasgupta@econ.cam.ac.uk>

This paper was presented at the James Meade Centenary meeting, July 12-13, 2007, Bank of England. We are grateful to David Vines and Martin Weale for their invitation to us to contribute to the occasion; to Tom Crossley, Andrew Oswald, and Robert Solow for helpful discussions; and to two anonymous referees for their comments and suggestions. 


\begin{abstract}
A growing body of empirical work suggests that a person's sense of well-being depends not only on his own consumption, but also on his consumption relative to the consumption of his reference group. It has been argued that because relative consumption matters to people, they must be involved in a "rat race": people work harder and consume more than they would have were optimum public policies in place. The problem with the argument is that if relative consumption matters, it should matter not only today, but also in the future. Consuming more today would improve one's relative consumption, other things being equal; but it would worsen one's relative consumption in the future. In this paper we identify the structure of utility functions for which the two effects offset each other exactly in a competitive economy. The finding goes some way toward explaining why, while household surveys suggest that relative consumption matters, the consumption behaviour of households has not pointed unambiguously to the presence of relative consumption effects. The finding also allows us to identify cases where the relative consumption effect amounts to people consuming and working more than their socially optimum levels and cases where the effect amounts to people consuming and working less. But the intuition that conspicuous consumption inevitably leads to a problem of "the commons" is mistaken.
\end{abstract}

JEL Classification: D62, D91, H23, I31

Keywords: happiness, felicity, relative consumption, social preference, externalities, status goods, waste, intertemporal competitive equilibrium, social optimum, representative agent. 
"... the utility of both (conspicuous leisure and conspicuous consumption) alike for the purposes of reputability lies in the waste that is common to both. In the one case it is a waste of time and effort, in the other it is a waste of goods. Both are methods of demonstrating the possession of wealth, and the two are conventionally accepted as equivalents."

Thorstein Veblen (1925), The Theory of the Leisure Class, George Allen \& Unwin (London), p.85.

\section{The Problem}

A growing body of empirical work suggests that contrary to what is customarily assumed in consumer demand theory, current consumption is not the only economic variable determining felicity (current utility). In an early work Duesenberry (1949) had explored the thesis that households care not only about their own consumption level, but also their consumption level relative to those of other households in their "reference group" (see also Leibenstein, 1950). Named the "demonstration effect", a person suffers felicity loss when others' consumption levels rise, because his relative consumption now declines.

It has even been suggested that, to those who are rich, only relative consumption matters (Layard, 2005). Surveys in which people were asked to report how happy or satisfied they were have confirmed that income matters to the poor (reported happiness was found on average to have increased with rising incomes), but they have also revealed that income does not contribute to reported happiness or satisfaction among people who have a good deal more than the basic necessities of life. Those who are poorer in rich countries say they are less happy; but even though those countries enjoyed economic growth in the periods covered in the samples, the distribution of declared happiness remained much the same. Clark et al. (2008), for example, report that since 1973 average life satisfaction in a number of European countries has remained approximately constant, even though real income per head in each country in the sample has 
increased sharply. If we are to take reported happiness (or satisfaction) at their face value, it would seem that happiness levels run flat through time as rich countries grow richer. The finding, noted first by Easterlin (1974), is today known widely as the Easterlin Paradox. ${ }^{1}$

It is possible to find explanations for the Easterlin Paradox that do not depend on people having "social" preferences. Easterlin (2001) has speculated that a person's aspirations increase with income, with the consequence that the happiness number he reports remains constant over his life cycle despite growth in income. One way to model that would be to suppose that past (or habitual) consumption influences his aspirations. In this interpretation, a person's reference group is his own past selves, not others.

An alternative way to model aspirations is to suppose that a person's felicity depends not only on his consumption level, but also the (percentage) rate of change of consumption. So, even when consumption rises over time, felicity would remain constant if the rate of growth in consumption were to decline at a rate that just cancels the improvement in the consumption level.

Although these alternative hypotheses can be used to confront the Easterlin Paradox (see Clark et al., 2008, for an assessment), they have very different theoretical implications. As neither habitual consumption nor the rate of change in one's own consumption involves interpersonal externalities, they do not give rise to economic distortions. Because relative consumption does involve such externalities, we should expect it to give rise to distortions. In this paper we identify those distortions.

Comparison of one's consumption with those of others can be made only if other people's

${ }^{1}$ Clark et al. (2008) record data on "happiness" from the General Social Survey and on "life satisfaction" from the Eurobarometer Survey. The authors review the Easterlin Paradox extensively. We are summarising a large and dispersed literature without noting the many qualifications that are embedded in the survey data (but see Section 5). For earlier reviews of the evidence, see Easterlin (1995, 2001), Oswald (1997), Blanchflower and Oswald (2004), and Layard (2005, 2006), among others. In this paper we use the terms happiness, satisfaction, well-being, welfare, and felicity interchangeably. 
consumptions are observable. Veblen's famous use of the adjective, conspicuous, draws attention to that requirement. Luttmer (2005) tested Veblen's thesis by matching panel data on selfreported happiness and other measures of well-being from the 1987-1988 and the 1992-1994 US National Survey of Families and Households. Controlling for individuals' personal incomes, he has found that higher earnings by neighbours are associated with lower levels of individual wellbeing. Nevertheless, it has proven hard to distinguish the conspicuous-consumption effect from the effect of common features or shocks within reference groups in data on household consumption. After accounting from correlated effects, Maurer and Meier (2008) have found only a moderate peer effect on household consumption in US micro data from the Panel Study of Income Dynamics. More recently, Kapteyn et al. (2007) have studied the consumption behaviour of winners of the Dutch Post Code Lottery and of people residing in adjacent post-code addresses. The study is of particular interest because their data come from a quasi-experiment where there are no confounding factors. The authors found that, although winning a lottery prize affected the consumption behaviour of winners, their win had essentially no effect on their neighbours' consumption behaviour.

Although Veblen's terminology is regularly invoked in the literature on competitive consumption, "conspicuous consumption" in Veblen's account plays an instrumental role in human behaviour, namely, as a way of signalling one's wealth to others in an environment where wealth is not observable. Wealth confers status and esteem; and conspicuous consumption is a way of displaying wealth. In this paper we bypass the signalling role by assuming simply that "conspicuous" consumption is among the economic variables in individuals' direct felicity functions. So, although we shall use Veblen's terminology here, we do not necessarily invoke the reasoning he deployed to explain why relative consumption matters to people. Our analysis is of course applicable in a world where conspicuous consumption is a signal of the unobservable 
wealth, but it is applicable more generally to a world where people feel bad if their consumption is less than that of others.

We include leisure among consumption goods. And although it can be questioned that leisure is observable, much leisure activity in the contemporary world involves conspicuous consumption (e.g., travel, entertainment). Veblen regarded leisure to be observable and wrote about "conspicuous leisure". We will consider leisure to be inconspicuous and conspicuous in turn.

Although Veblen suggested that in advanced societies conspicuous leisure takes the form of elaborate and costly idleness, it has been widely argued in the recent literature that if conspicuous consumption matters to people, the economic distortion must take the form of a "rat race": people work harder and consume more than they would if ideal public policies were in place. $^{2}$ The implication is that well-chosen public policies to discourage consumption (e.g., a general consumption tax (Layard, 2005) or restrictions on working hours (Alvarez-Cuadrado, 2007)) would be welfare enhancing. Although seemingly plausible, the intuition that conspicuous consumption leads to excess is unreliable. Consider a world where labour is supplied inelastically. If individuals are forward looking, they would know that conspicuous consumption matters to them not only today but will matter to them also in the future. They would then realise that, although consuming more today would improve their relative standing now, it would worsen their relative standing in the future. Individuals will wish to strike a balance between their conflicting desires. In this paper we study how the structure of felicity functions mediates that

${ }^{2}$ See Frank (1985a,b), Ng (1987), Howarth (1996), Schor (1998), Layard (2005, 2006), and Ali Choudhary and Levine (2006). A formal growth model with biases in technological advances toward "status goods" is developed in Cooper, Garcia-Penalosa, and Funk (2001). 
intertemporal conflict. $^{3}$

Two questions arise: (1) Do the externalities associated with conspicuous consumption's role as a variable determining felicity give rise to economic distortions? (2) Other things being equal, do people work harder and consume more in societies where conspicuous consumption is a factor of greater importance in individual felicity?

Question (2), even if the answer to it happens to be in the affirmative, sits uncomfortably in contemporary policy analysis. Felicity functions are customarily taken to be given and regarded as the basis on which public policies ought to be fashioned. But there are social scientists (most prominently, Layard, 2005) who have argued that education and "happiness enhancing" activities offer ways to dilute the effect of conspicuous consumption on personal well-being. In this paper we investigate question (1). We do that by studying the effect of conspicuous consumption on the mix of personal consumption, leisure, and saving in an intertemporal economy. As would be expected, answering (1) produces the machinery to answer (2) as a byproduct.

Our formulation, however, incorporates a wider set of concerns than biases in intertemporal consumption. The model we construct enables us to study possible biases in the consumption of "status goods" more generally in market economies. To illustrate our basic argument, consider a timeless, competitive economy that produces two goods, both of which are objects of conspicuous consumption. Let the ratio of household $i$ 's marginal felicity of own consumption of commodity 1 (resp. 2) to $i$ 's marginal felicity of the economy-wide average consumption of 1 (resp. 2) be $\alpha_{1 i}$ (resp. $\alpha_{2 i}$ ). Clearly, if $\alpha_{1 i}=\alpha_{2 i}$ for all $i$, market equilibrium

\footnotetext{
${ }^{3}$ The idea that conspicuous consumption might have pro-savings as well as pro-consumption effects was first suggested to one of the authors (K.J.A.) by the late Hendrik Houthakker some fifty years ago. We take this opportunity to express our gratitude to him.

${ }^{4}$ The finding of "happiness surveys" is that $\alpha_{1 i}, \alpha_{2 i}<0$.
} 
would be Pareto optimal. In this paper we study the implications of that basic fact for an intertemporal economy.

Our model is that of a production economy comprising a continuum of infinitely-lived households. The plan of the paper is as follows:

In Section 2 we study an economy where labour is supplied inelastically. Consumption is conspicuous and household felicity is assumed to depend not only on the household's own consumption rate, but also on its consumption rate relative to the average rate of consumption in the economy. Households are assumed to be identical (but see Section 4). Household utility is the discounted sum of felicities from the present to the indefinite future. We analyse competitive (market) equilibrium consumption paths. Assuming that social welfare is the sum of household utilities, we next identify socially optimal consumption programmes. In Proposition 1 we identify a class of felicity functions for which conspicuous consumption creates no distortion; that is, consumption in market equilibrium is socially optimal. Earlier we noted that although analyses of "happiness surveys" have pointed strongly to the importance of relative consumption in household felicity, recent econometric studies have found little evidence that relative consumption affects household consumption behaviour. Proposition 1 offers us a way to reconcile the two sets of findings: even when relative consumption matters, it can be that there is no market distortion.

Labour supply is taken to be subject to household choice in Section 3. In Section 3.1 consumption is assumed to be conspicuous, but not leisure, which is assumed to be inconspicuous. We are able to show that, at the stationary state of market equilibrium, households consume more and work longer than they would at the stationary state of the socially optimal path (Proposition 2). In Section 3.2 both consumption and leisure are assumed to be conspicuous. Proposition 3 identifies a class of felicity functions for which consumption and leisure in market 
equilibrium are at their socially optimal levels. The proof of the proposition allows us to identify a class of felicity functions for which consumption and leisure in market equilibrium are less (respectively, more) than their socially optimal levels. ${ }^{5}$ In an early work, Layard (1980) studied a two-period model of consumption and leisure, in which both consumption and leisure are conspicuous. Proposition 3 below generalises his finding to a fully intertemporal setting.

The assumption that households are identical could seem unduly restrictive. In Section 4 we identify conditions on the determinants of intertemporal budget constraints under which the "representative" household model can be justified. Our result extends the work of Lucas and Stokey (1984) to competitive economies with externalities. The propositions in Sections 2-3 should therefore be interpreted to be answers to the question whether consumption and leisure choices in competitive equilibrium are Pareto optimal, even when both consumption and leisure are conspicuous.

Taken together, empirical work on consumption behaviour and on the responses people make to questions about happiness and life satisfaction has generated a number of puzzles. Proposition 1 offers a way to resolve one puzzle, by showing that even when relative consumption matters to people, their behaviour need not reflect it. On the other hand, it would seem that many seemingly unrelated factors must come together in rather precise ways if the Easterlin Paradox is to be explained (Clark et al., 2008). So one should ask whether some of the puzzles are generated by the fact that the empirical data cover a disparate range and may not even be comparable. In Section 5 we study this possibility.

Because we want to focus on the role played by the structure of felicity functions (Propositions 1-3), we work with the simplest technology in the body of the paper. We assume

\footnotetext{
${ }^{5}$ In an interesting paper, Alvarez-Cuadrado (2007) has quantified the welfare losses associated with conspicuous consumption when the condition identified in Proposition 3 does not hold.
} 
that the technology is convex and involves a single type of labour and a single reproducible, nondeteriorating capital good that serves also as a consumption good. In the Appendix we show that Propositions 1-3 hold under considerably more general production structures. We hope that the techniques we develop for deriving our results will prove useful for studying other questions of intertemporal welfare economics.

\section{Pure Consumption}

There is a continuum of infinitely lived households, indexed by $i$, who are distributed uniformly in the unit interval. Households are identical. We normalise by setting population size at 1 . Time is continuous and denoted by $t(\geq 0)$. Labour is supplied inelastically. Other than labour, the economy consists of an all-purpose non-deteriorating commodity that can be either consumed or accumulated. ${ }^{6}$ If $K(t)$ is the stock of capital at $t$, instantaneous output is assumed to be $F(K(t))$, where $F$ is an increasing and strictly concave function of $K \cdot^{7} F(0)=0$. Let $c^{i}(t)$ denote household $i$ 's consumption rate at $t$. Define

$$
C(t)={ }_{0}{ }^{1} c^{i}(t) \mathrm{d} i .
$$

$C(t)$ is average consumption of the population at $t$.

\subsection{The Model}

Let $U^{i}\left(c^{i}, C\right)$ be household $i$ 's felicity function. As households are identical, we write $U^{i}\left(c^{i}, C\right)=U\left(c^{i}, C\right)$. Assume that

$U$ is strictly concave in $c^{i}$ for all $C$, concave when both $c^{i}$ and $C$ increase together; (2a)

and $\quad U_{c}\left(c^{i}, C\right)>0$, and $U_{C}\left(c^{i}, C\right)<0{ }^{8}$

\footnotetext{
${ }^{6}$ The analysis is extended to cover multiple consumption goods (Section 4) and multiple capital assets (Appendix).

${ }^{7}$ The arguments that follow hold even if the economy enjoys exogenuous technological progress.

${ }^{8} U_{c}\left(c^{i}, C\right) \equiv \partial U / \partial c^{i}$ and $U_{C}\left(c^{i}, C\right) \equiv \partial U / \partial C$. We also assume that the elasticity of $U_{c}$ is bounded for every $C$ and, in order that corner solutions are avoided, that, for all $C, U_{c}\left(c^{i}, C\right) \rightarrow \infty$ as $c^{i} \rightarrow 0$.
} 
Household $i$ 's (intertemporal) utility at $\mathrm{t}=0$ is

$$
W^{i}:={ }_{0}{ }^{\infty} \exp (-\delta t) U\left(c^{i}(t), C(t)\right) \mathrm{d} t, \quad \delta>0 .
$$

Social welfare at $\mathrm{t}=0$ is the sum of household utilities; that is,

$$
W:={ }_{0}{ }^{1}\left[{ }_{0} \int^{\infty} \exp (-\delta t) U\left(c^{i}(t), C(t)\right) \mathrm{d} t\right] \mathrm{d} i .
$$

We now characterise market equilibrium and socially optimal paths. ${ }^{9}$ Condition (2a) and the concavity of $F$ imply that households behave identically along each path. So,

$$
c^{i}(t)=c(t)=C(t)
$$

The accumulation equation for the representative household can therefore be expressed

as,

$$
\mathrm{d} K / \mathrm{d} t=F(K(t))-c(t), \quad \text { where } K(0) \text { is given. }
$$

Let $p(t)$ be the spot price of capital. In view of (3), the current-value Hamiltonian is,

$$
H(t)=U(c(t), C(t))+p(t)[F(K(t))-c(t)]
$$

and $p(t)$ satisfies the equation of motion,

$$
[\mathrm{d} p(t) / \mathrm{d} t] / p(t)=\delta-F_{K} .
$$

Note that equation (6) and its dual (equation (8), which represents the dynamics of the shadow price of capital) are valid for both the socially optimum and market equilibrium paths.

Consider first the market equilibrium path. ${ }^{10}$ Households take the time path of $C(t)$ as given and maximise (7) with respect to $c(t)$ at each $t$. In equilibrium, condition (5) holds. Let the superscript " $m$ " denote "market equilibrium". We then have

$$
U_{c}\left(C^{m}(t), C^{m}(t)\right)=p^{m}(t)
$$

where $p^{m}(t)$ satisfies condition (8).

\footnotetext{
${ }^{9}$ We do not study the existence of either equilibrium or optimal paths because the relevant theorems in Stokey and Lucas (1989) can be used to show that they do exist under the conditions we have placed on preferences and technology.

${ }^{10}$ In view of the assumptions we have made on $F$ and $U$, equilibrium is unique.
} 
Now consider the socially optimal path. In view of (4), the social planner maximizes (7) by choosing both $c(t)$ and $C(t)$, while acknowledging conditions (5). Let the superscript " $o$ " denote "optimum". It follows that

$$
U_{c}\left(C^{o}(t), C^{o}(t)\right)+U_{C}\left(C^{o}(t), C^{o}(t)\right)=p^{o}(t),
$$

where $p^{o}(t)$ satisfies condition (8).

Under what conditions are the market equilibrium and socially optimal paths the same? For the two to be identical, the right-hand side of equation (8) must be the same along the two paths, implying that

$$
\left[\mathrm{d} p^{m}(t) / \mathrm{d} t\right] / p^{m}(t)=\left[\mathrm{d} p^{o}(t) / \mathrm{d} t\right] / p^{o}(t),
$$

and therefore,

$$
p^{o}(t) / p^{m}(t)=\gamma, \quad \text { where } \gamma \text { is a positive constant. }
$$

Because $U_{C}\left(C^{o}(t), C^{o}(t)\right)<0$, we know from equation (10) that $U_{c}\left(C^{o}(t), C^{o}(t)\right)>p^{o}(t)$. Let $\beta=\gamma-1$. We now divide (10) by (9) and use (12) to obtain

Proposition 1. Assume that the felicity function of the representative household satisfies conditions (2a-b). The socially optimal and market equilibrium paths coincide if, and only if, there exists a constant $\beta(-1<\beta<0)$, such that

$$
U_{C}(C, C)=\beta U_{c}(C, C), \quad \text { for all } C .
$$

Corollary. If condition (13) holds, then $U(C, C)$ increases with $C$.

Proof: $\mathrm{d} U(C, C) / \mathrm{d} C=U_{c}(C, C)+U_{C}(C, C)=(1+\beta) U_{c}(C, C)>0 . \|$

The Corollary says that, if $c=C$, the absolute value of the negative effect of others' consumption is less than the gains from one's own consumption.

Blanchflower and Oswald (2004) have estimated from the General Social Surveys of the United States that a person's sense of well-being there would increase if everyone's income (consumption) were to increase proportionately, but only by two-thirds as much as it would if 
only his income (consumption) were to increase by that same proportion. To put it formally, if $g$ is a percentage change,

$$
U\left((1+g) c^{i},(1+g) C\right)-U\left(c^{i}, C\right)=2 / 3\left[U\left((1+g) c^{i}, C\right)-U\left(c^{i}, C\right)\right],
$$

implying that $-1<\beta<0$. In contrast, the Easterlin Paradox would obtain exactly if $\beta=-1$. So we have an empirical puzzle here.

\subsection{Examples}

It is instructive to study special forms of the felicity function for which Proposition 1 holds.

(a) Additive felicities

Suppose that

$$
U(c, C)=V(c)+Z(C) \text {, where } V \text { is concave and } V^{\prime}(c)>0 .
$$

Condition (13) implies that

$$
Z^{\prime}(C)=\beta V^{\prime}(C),
$$

which in turn implies that

$$
Z(C)=\beta V(C)+\text { constant }
$$

It follows that

$$
U(C, C)=(1+\beta) V(C),
$$

which is concave by assumption.

(b) Multiplicative felicities

Suppose that

$$
U(c, C)=V(c) Z(C), \text { where } V \text { is concave and } V^{\prime}(c)>0 .
$$

Condition (13) implies that

$$
Z^{\prime}(C) / Z(C)=\beta V^{\prime}(C) / V(C) .
$$

But it may be that $V$ or $Z$ is negative. That being so, equation (17) can be restated as 


$$
\mathrm{d}(\ln |Z(C)|) / \mathrm{d} C=\beta \mathrm{d}(\ln |V(C)|) / \mathrm{d} C,
$$

implying that

$$
|Z(C)|=A|V(C)|^{\beta}, \quad A>0 \text { and }-1<\beta<0 .
$$

An example of (18) is

$$
U(c, C)=c^{1-\mu} C^{(1-\mu) \beta} /(1-\mu), \quad \mu>1 \text { and }-1<\beta<0 .
$$

In (19) the elasticity of marginal utility of own consumption and the elasticity of marginal utility of average consumption are constant.

(c) Felicity as a function of own consumption adjusted for average consumption

Suppose that

$$
U(c, C)=V(c Z(C)), \quad \text { where } V \text { is concave and } V^{\prime}>0 \text {. }
$$

Condition (13) implies that

$$
Z^{\prime}(C) / Z(C)=\beta / C,
$$

and so

$$
Z(C)=A C^{\beta}, \quad \mathrm{A}>0 \text { and }-1<\beta<0 .
$$

Equations (20) and (21) imply that

$$
U(C, C)=V\left(A C^{(1+\beta)}\right) .
$$

As $A C^{(1+\beta)}$ is an increasing concave function of $C$, and $V$ is an increasing concave function, $U(C, C)$ is an increasing concave function of $C$.

The limiting case, $\beta=-1$, which we have prohibited here, is noteworthy, in that it harbours a continuum of optimum paths. As only relative consumption matters for this limiting case, all feasible paths for which $c_{i}(t)=C(t)$, for all $i$, are socially optimal.

\section{Consumption and Leisure}

So far we have assumed that household labour supply is inelastic. We now suppose it is not. Let $e^{i}(t)\left(0 \leq e^{i} \leq 1\right)$ be the labour (or effort) supplied by household $i$ at time $t$. Aggregate 
effort, $E(t)$, is

$$
E(t)={ }_{0}^{\int}{ }^{1} e^{i}(t) \mathrm{d} i .
$$

The production function of the single reproducible commodity is $F(K, E)$, where $F$ is concave, increasing, and homogeneous of degree one in $K$ and $E .^{11}$ In view of our demographic assumptions, $0 \leq E \leq 1$.

As output can be used either for capital accumulation or consumption, $K$ 's equation of motion is,

$$
\mathrm{d} K(t) / \mathrm{d} t=F(K(t), E(t))-C(t) .
$$

\subsection{Inconspicuous leisure}

We now assume that, although other people's consumptions are conspicuous, the leisure other people enjoy is inconspicuous. If $e^{i}$ is the labour supplied by household $i$, the leisure it enjoys is $\left(1-e^{i}\right)$. We write $i$ 's felicity function as,

$$
U\left(c^{i}, C\right)-V\left(e^{i}\right),
$$

where $V$ is an increasing and strictly convex function of $e^{i}$ and, as previously, $U\left(c^{i}, C\right)$ satisfies conditions $(2 \mathrm{a}-\mathrm{b}) .{ }^{12}$

Taking our lead from Proposition 1, assume that there is a constant, $\beta(-1<\beta<0)$, such that,

$$
U_{C}(C, C)=\beta U_{c}(C, C) \text {, for all } C \text {. }
$$

Household $i$ 's intertemporal utility is

$$
W^{i}:={ }_{0}{ }^{\infty} \exp (-\delta t)\left[U\left(c^{i}(t), C(t)\right)-V\left(e^{i}(t)\right)\right] \mathrm{d} t, \quad \delta>0
$$

and social welfare is

$$
W:={ }_{0} \int^{1}\left\{{ }_{0} \int^{\infty} \exp (-\delta t)\left[U\left(c^{i}(t), C(t)-V\left(e^{i}(t)\right)\right] \mathrm{d} t\right\} \mathrm{d} i .\right.
$$

${ }^{11}$ We write $F_{K}=\partial F / \partial K$ and $F_{E}=\partial F / \partial E$. So as to avoid corner solutions, assume that $F_{K}$ and $F_{E}$ are unbounded as $K$ and $E \rightarrow 0$, respectively.

${ }^{12}$ In order to avoid corner solutions in what follows, it is assumed that $V^{\prime}(e) \rightarrow 0$ as $e \rightarrow 0$ and $V^{\prime}(e) \rightarrow$ $\infty$ as $e \rightarrow 1$. 
We first identify the market equilibrium:

Household $i$ takes the time paths of $C(t)$ and $E(t)$ as given and maximizes (27) with respect to $c^{i}(t)$ and $e^{i}(t)$ for all $t$, subject to (24). In equilibrium,

$$
c^{i}(t)=c(t)=C(t) \text { and } e^{i}(t)=e(t)=E(t) .
$$

Therefore, using equations (24) and (27) we can express the current-value Hamiltonian as,

$$
H(t)=\left[U\left(c^{i}(t), C(t)\right)-V\left(e^{i}(t)\right)\right]+p(t)[F(K(t), E(t))-C(t)]
$$

where $p(t)$ is the co-state variable, satisfying its equation of motion,

$$
[\mathrm{d} p(t) / \mathrm{d} t] / p(t)=\delta-F_{K}(K(t), E(t)) .
$$

As previously, let the superscript " $m "$ on a variable denote "market equilibrium". Maximizing (30) with respect to $c^{i}(t)$ and $e^{i}(t)$, and using (29) yields

$$
U_{c}\left(C^{m}(t), C^{m}(t)\right)=p^{m}(t),
$$

and $\quad V^{\prime}\left(E^{m}(t)\right)=p^{m}(t) F_{E}\left(K^{m}(t), E^{m}(t)\right)$.

The equations of motion (24), (31), and (32)-(33) possess a (unique) stationary point, $\left(K^{m *}, p^{m *}, C^{m *}, E^{m *}\right)$.

We identify the socially optimal path next:

The planner maximizes (28) with respect to $c^{i}(t)$ and $e^{i}(t)$ for all $i$ and $t$ subject to equation (24). From the concavity of the functions $U(C, C),-V(e)$, and $F(K, E)$, we know that (29) is satisfied along the optimal path. Therefore, using equations (24) and (28), we can express the current-value Hamiltonian as,

$$
H(t)=[U(C(t), C(t))-V(E(t))]+p(t)[F(K(t), E(t))-C(t)],
$$

where $p(t)$ is the co-state variable, satisfying the equation of motion (31). As previously, let the superscript " $o$ " denote "optimum". Maximizing (34) with respect to $C(t)$ and $E(t)$ yields

$$
U_{c}\left(C^{o}(t), C^{o}(t)\right)+U_{C}\left(C^{o}(t), C^{o}(t)\right)=p^{o}(t),
$$

and $\quad V^{\prime}\left(E^{o}(t)\right)=p^{o}(t) F_{E}\left(K^{o}(t), E^{o}(t)\right)$. 
The equations of motion (24), (31), and (35)-(36) possess a (unique) stationary point, $\left(K^{o *}, p^{o *}, C^{o *}, E^{o *}\right)$.

We can now state

Proposition 2. $C^{m *}>C^{o *}, E^{m_{*}}>E^{o *}$, and $K^{m_{*}}>K^{o *}$.

Proof: Let us combine the pair of equations, (32) and (35) into a single, one-parameter $(\mu)$ family,

$$
U_{c}(C(t), C(t))+\mu U_{C}(C(t), C(t))=p(t) .
$$

Equation (38) reduces to the equilibrium condition (32) for $\mu=0$ and to the optimality condition (35) for $\mu=1$. For our purposes, though, it will prove useful to transform the parameter. If we define $v$ as,

$$
v=(1+\mu \beta) /(1+\beta)
$$

equation (38) can be written, with the aid of condition (26), as

$$
v\left[U_{c}(C(t), C(t))+U_{C}(C(t), C(t))\right]=p(t) .
$$

Moreover, the common form of conditions (33) and (36) is,

$$
V^{\prime}(E(t))=p(t) F_{E}(K(t), E(t))
$$

The combined dynamical system is defined by equations (24), (31), (40), and (41).

Let $k=K / E$ (capital-labour ratio). Define $f(k)=F(K, E) / E$. $f$ is an increasing and concave function of $k$, with $f(0)=0$. Moreover, $F_{K}(K, E)=f^{\prime}(k)$ and $F_{E}(K, E)=f(k)-k f^{\prime}(k)$. Therefore, at the stationary state $(*)$ of our dynamical system, equations (24) and (31) reduce to

$$
F\left(K^{*}, E^{*}\right)=f\left(k^{*}\right) E^{*}=C^{*},
$$

and

$$
F_{K}\left(K^{*}, E^{*}\right)=f^{\prime}\left(k^{*}\right)=\delta .
$$

Equation (43) tells us that $k^{*}$ is independent of $\mu$; and equation (42) says that $C^{*}$ is proportional to $E^{*}$, independently of $\mu$. Eliminating $p(t)$ from (40) and (41), and writing $p(t)=p^{*}$, yields

$$
V^{\prime}\left(E^{*}\right)=v\left(f\left(k^{*}\right)-k^{*} f^{\prime}\left(k^{*}\right)\right)\left[U_{c}\left(C^{*}, C^{*}\right)+U_{C}\left(C^{*}, C^{*}\right)\right] .
$$


As $V$ is an increasing and strictly convex function of $E, V^{\prime}(E)$ is an increasing function of $E$. Since $U(C, C)$ is concave, $\left[U_{c}\left(C^{*}, C^{*}\right)+U_{C}\left(C^{*}, C^{*}\right)\right]$ is a decreasing function of $C^{*}$ and, so, from equation (42), it is a decreasing function of $E^{*}$. It follows from equation (44) that $C^{*}$ and $E^{*}$ are increasing functions of $\nu$ and, from (39) that they are both decreasing functions of $\mu$. Consequently, $C^{m *}>C^{o *}, E^{m *}>E^{o *}$ and, from (43), $K^{m *}>K^{o *} . \|$

\subsection{Conspicuous leisure}

Suppose that leisure is conspicuous and that household $i$ 's felicity function is

$$
U\left(c^{i}, C\right)-V\left(e^{i}, E\right)
$$

where (i) $U$ satisfies conditions (2a-b), (ii) $V_{e}\left(e^{i}, E\right)>0$, and $V_{E}\left(e^{i}, E\right)<0,{ }^{13}$; (iii) $V_{e}(E, E)+V_{E}(E, E)$ $>0$ for all $E$; and (iv) $V$ is strictly convex in $e^{i}$ for all $E$ and convex when both $e^{i}$ and $E$ increase together.

We wish to uncover conditions on $U$ and $V$ under which the market equilibrium and the socially optimal paths are identical. Taking the lead from condition (13), assume that there exists a constant $\gamma(-1<\gamma<0)$ such that for all $E$,

$$
V_{E}\left(e^{i}, E\right)=\gamma V_{e}\left(e^{i}, E\right) .
$$

In what follows, we study the stationary points $(*)$ of the two paths. Retracing the arguments in Section 3.1, we now have, in place of condition (33),

$$
V_{e}\left(E^{m *}, E^{m *}\right)=p^{m *} F_{E}\left(K^{m *}, E^{m *}\right) \quad \text { (equilibrium condition) }
$$

and in place of condition (36),

$$
V_{e}\left(E^{o *}, E^{o *}\right)+V_{E}\left(E^{o *}, E^{o *}\right)=p^{o *} F_{E}\left(K^{o *}, E^{o *}\right) \quad \text { (optimality condition) }
$$

As before, we embed (47)-(48) into a one-parameter family

$$
V_{e}\left(E^{*}, E^{*}\right)+\mu V_{E}\left(E^{*}, E^{*}\right)=p^{*} F_{E}\left(K^{*}, E^{*}\right)
$$

${ }^{13} V_{e}\left(1-e^{i}, 1-E\right) \equiv \partial V / \partial e^{i}$ and $V_{C}\left(1-e^{i}, E\right) \equiv \partial V / \partial E$. Analogous to (2b), we also assume that the elasticity of $V_{e}$ is bounded for every $E$ and, in order that corner solutions are avoided, that, for all $E, V_{e}\left(e^{i}, E\right) \rightarrow \infty$ as $e^{i} \rightarrow 1$ and $V_{e}\left(e^{i}, E\right) \rightarrow 0$ as $e^{i} \rightarrow 0$. 
where $\mu=0$ and $\mu=1$ correspond to "equilibrium" and "optimal", respectively. Analogous to (39) we next define a new parameter $v^{E}$ as

$$
v^{E}=(1+\mu \gamma) /(1+\gamma)
$$

and, analogous to equation (40), we have

$$
v^{E}\left[V_{e}\left(E^{*}, E^{*}\right)+V_{E}\left(E^{*}, E^{*}\right)\right]=p^{*} F_{E}\left(K^{*}, E^{*}\right) .
$$

For vividness, let $v$ in (39) be now written as $v^{C}$. Eliminating $p^{*}$ between equations (40) and (51) and writing $v=v^{C} / v^{E}$ yields

$$
V_{e}\left(E^{*}, E^{*}\right)+V_{E}\left(E^{*}, E^{*}\right)=v F_{E}\left(K^{*}, E^{*}\right)\left[U_{c}\left(C^{*}, C^{*}\right)+U_{C}\left(C^{*}, C^{*}\right)\right] .
$$

By the assumptions made on $V$, the left-hand side of equation (52) is increasing in $E^{*}$. By the concavity assumptions on $U$, the right-hand side is decreasing in $C^{*}$. Moreover, $C^{*}$ is proportional to $E^{*}$. Hence $C^{*}$ and $E^{*}$ increase as $v$ increases. But $\nu$ decreases with $\mu$ if $\beta<\gamma$ and increases with $\mu$ if $\beta>\gamma$. (Recall that $\beta$ and $\gamma$ are both negative.) Hence, optimal stationary consumption is lower than equilibrium stationary consumption and optimal stationary leisure is higher than equilibrium stationary leisure if $\beta<\gamma$, while the opposite holds if $\beta>\gamma$. From (43) we also conclude that the optimum stationary capital stock is lower than the equilibrium stationary capital stock if $\beta<\gamma$, while the opposite holds if $\beta>\gamma$. The two stationary states are the same if $\beta=\gamma$. The reasoning we deployed in Section 2 can be used to show that the argument extends outside the stationary state. We then have

Proposition 3. If the felicity function of the representative household, $U\left(c^{i}, C\right)-V\left(e^{i}, E\right)$, satisfies condition (45), the socially optimal and market equilibrium paths coincide if, and only if, there exists a constant $\beta(-1<\beta<0)$, such that

$$
U_{C}(C, C)=\beta U_{c}(C, C), \quad \text { for all } C
$$

and $\quad V_{E}\left(e^{i}, E\right)=\beta V_{e}\left(e^{i}, E\right) \quad$ for all $E$.

Proposition 3 says though that the externalities associated with conspicuous consumption 
and conspicuous leisure cancel if the household's felicity function satisfies two conditions: (i) when the household's own consumption is the economy's average, the marginal felicity of its consumption is proportional to the marginal dis-felicity of the average consumption level; and (ii) the constant of proportionality is the same for consumption as well as leisure. Condition (ii) characterizes a particular form of symmetry. It says the externalities are the same for consumption and leisure.

\section{Justifying the representative household model ${ }^{14}$}

So far we have assumed that households are identical. We need to justify that. Let us then suppose that households are heterogeneous. In Section 3 it was confirmed that we have no need to assume the existence of a single consumption good. Suppose then that there are multiple consumption and capital goods. As we are studying competitive markets, we take it that the aggregate production of goods and services depends only on the aggregate stocks of capital assets and labour services.

Let $\underline{c}^{i}(t)$ be the consumption vector of household $i$ at $t . \underline{c}^{i}(t)$ includes leisure as one of its components. Define

$$
\underline{C}(t)={ }_{0}{ }^{1} \underline{c}^{i}(t) \mathrm{d} i .
$$

$\underline{C}(t)$ is the vector of average consumptions.

Household $i$ 's felicity function is denoted by

$$
U^{i}\left(\underline{c}^{i}, \underline{C}\right),
$$

where $U^{i}\left(\underline{c}^{i}, \underline{C}\right)$ satisfies conditions (2a-b) for each component of $\underline{c}^{i}$ and $\underline{C}$, respectively.

Consider first market equilibria. Since aggregate production is a function of only aggregate stocks of capital assets and aggregate labour services, equilibrium prices depend only

\footnotetext{
${ }^{14}$ The argument we develop here is an extension of the one used in Lucas and Stokey (1984) for Pareto optimal allocations without externalities.
} 
on those aggregates. As markets are competitive, the aggregate consumption vector is exogenous to each household. To emphasize that, we replace $\underline{C}$ by $\underline{C}^{m}$ in (54). In equilibrium, each household, $i$, maximizes

$$
W^{i}:={ }_{0}{ }^{\infty} \exp (-\delta t) U^{i}\left(\underline{c}^{i}(t), \underline{C}^{m}(t)\right) \mathrm{d} t, \quad \delta>0,
$$

where $\underline{C}^{m}(t)=\underline{C}(t)$ and $\underline{C}(t)$ is defined by (53).

The market equilibrium we are studying is a competitive equilibrium. Therefore, given $\underline{C}^{m}(t)$, the equilibrium allocation is Pareto optimal. It follows that there exists a set of positive weights, $w^{i}$, such that, the equilibrium allocation maximizes,

$$
W:={ }_{0} \int^{\infty} w^{i} W^{i} \mathrm{~d} i
$$

In competitive equilibrium, household $i$ will have maximized $W^{i}$ subject to a budget constraint that is determined by prices and $i$ 's initial assets. But by our earlier assumption on the structure of production and consumption, equilibrium prices depend only on aggregate incomes and consumptions; which means that the household budget constraints can also be aggregated. Therefore, the market equilibrium allocation we are studying maximizes $W$ subject to an aggregate budget constraint. Substituting (55) in (56) yields

$$
W={ }_{0}{ }^{1}\left[{ }_{0}{ }^{\infty} \exp (-\delta t) w^{i} U^{i}\left(\underline{c}^{i}(t), \underline{C}^{m}(t)\right) \mathrm{d} t\right] \mathrm{d} i, \quad \delta>0 .
$$

Since only $\underline{C}(t)$ appears in the aggregate budget constraint (the individual $\underline{c^{i}}(t)$ 's do not appear in it), the maximization of $W$ involves, as a step, choosing $c^{i}(t)$ so as to maximize

$$
{ }_{0}^{\int}{ }^{1} \exp (-\delta t) w^{i} U^{i}\left(\underline{c}^{i}(t), \underline{C}^{m}(t)\right) \mathrm{d} i
$$

for each t, subject to (53).

Define

$$
U\left(C(t), C^{m}(t)\right):=\max _{0} \int^{1} w^{i} U^{i}\left(\underline{c}^{i}(t), \underline{C}^{m}(t)\right) \mathrm{d} i, \quad \text { subject to (53). }
$$

$U(c, C)$, thus constructed, satisfies conditions (2a-b) if $U^{i}\left(\underline{c^{i}}, \underline{C}\right)$ satisfies them for all $i$. Moreover, $U$ is such that the maximization of $W$ subject to the aggregate budget constraint is equivalent to 
the maximization of

$$
{ }_{0}^{\int^{\infty}} \exp (-\delta t) U\left(\underline{C}(t), \underline{C}^{m}(t)\right) \mathrm{d} t
$$

subject to the equilibrium condition $\underline{C}(t)=\underline{C}^{m}(t) . U\left(\underline{c}(t), \underline{C}^{m}(t)\right)$ can thus be interpreted as the felicity function of the representative household.

A parallel argument applies for the optimal solution, yielding the same felicity function

$U(\underline{c}, \underline{C})$. The one difference in the steps to be taken is that the condition $\underline{C}(t)=\underline{C}^{m}(t)$ should be replaced by the constraint $\underline{C}(t)=\underline{C}^{o}(t)$, the latter vector being the optimal aggregate consumption of goods and services.

\section{Discussion}

Veblen (1925: 36) argued that "In order to gain and to hold the esteem of men it is not sufficient merely to possess wealth or power. The wealth or power must be put in evidence, for esteem is awarded only on evidence."

Ireland (1994) and Bagwell and Bernheim (1996), among others, have developed Veblen's thesis by constructing models in which people care about their status. If status is confered by wealth and if wealth is unobservable, conspicuous consumption could be a means adopted by people to signal their wealth relative to that of others in their reference group. In simple, timeless models that invoke status as a commodity, it can be shown that conspicuous consumption rises with one's own income, but declines with the average income of one's reference group. Charles et al. (2007) have found evidence of this. Using data from the Consumer Expenditure Survey in the US during 1986-2002, they found that, controlling for differences in permanent incomes, Blacks and Hispanics spend about 30\% more on conspicuous consumption (e.g., jewelery) than Whites. The authors also found a strong negative association between conspicuous consumption and the mean income of one's reference group within all races. Where does that extra expenditure come from? The authors found that the higher spending on conspicuous consumption is at the 
expense of both future consumption and inconspicuous current consumption. Our Proposition 2 is indicative of that finding.

The model we have developed in this paper incorporates the desire for status, but it is applicable more widely; which is why we have called consumption "conspicuous" when a person's consumption relative to the average matters to the individual and is observable by others. Earlier we noted that although analyses of surveys have pointed strongly to the importance of relative consumption in household felicity, several recent econometric studies have found little evidence that relative consumption affects household consumption behaviour. Proposition 1 offers us a way to reconcile the two sets of findings: even when relative consumption matters, it can be that there is no market distortion. The underlying intuition is clear: if the marginal felicity of own consumption of each good is negatively proportional to the marginal felicity of economy-wide average consumption of that good and if the constant of proportionality is the same for all goods, the market would harbour no distortion.

The enormous diversity of empirical findings on happiness and consumption (see in particular the survey by Clark et al., 2008), however, should be interpreted cautiously. There are at least five questions that can be, and have been, used as possible entry points in empirical research and policy analysis on consumption and leisure. Even though the questions are distinct and may not even be closely related, they are often taken to be tightly linked to one another. The questions are:

(a) What is the human good?

(b) What do people care about?

(c) What do people say when asked how they are, or how they feel?

(d) What considerations do people take into account when choosing?

(e) What do they choose? 
It is tempting to assume that one may move seamlessly from (a) to (e). But (a) is a deep question in ethics, whereas (c) is about the responses people make to questionnaires and (d) and (e) involve the psychology and sociology of behaviour. As there are potential bottlenecks at each link in the chain leading from (a) to (e), it could be that some of the puzzles in the theory and empirics of consumption are not puzzles after all.

For example, the happiness surveys themselves could be suspect (i.e. one could suspect that eliciting (c) is not a way to determine (b)). On the other hand, if we wish to maintain the methodological stance that there is a straight route from (a) to (e) and also regard happiness to be the human good, we need to identify another factor that influences human happiness, one that has been worsening in rich countries and which reconciles the Easterlin Paradox with Proposition 1 and its Corollary. It is not easy to see what that missing factor could be.

We noted earlier that one possibility is to introduce aspirations into human motivation (Easterlin, 2001). The Easterlin Paradox would evaporate if aspirations are continually frustrated in modern societies and if that frustration cancels the gains from increasing wealth among wealthy households.

A way to model aspirations is to include past consumption experiences in current felicity; or in other words that households are subject to habit formation. A simple method of doing that is to include the discounted sum of past consumptions in current household felicity (Ryder and Heal, 1973). The presence of past consumption in current felicity introduces an intertemporal externality, namely, the influence of one's past selves on one's present self. But it is an externality that would be internalized by rational households.

Veblen (1925: 31) included habit in his analysis of consumption: "But as fast as a person makes new acquisitions, and becomes accustomed to the resulting new standard of wealth, the new standard forthwith ceases to afford appreciably greater satisfaction than the earlier standard 
did. The tendency ... is constantly to make the present pecuniary standard the point of departure for a fresh increase in wealth; and this in turn gives rise to a new standard of sufficiency and a new pecuniary classification of one's self as compared with one's neighbours."

Establishing that consumption behaviour is influenced by habit has proved to be problematic though. Dynan (2000) found no evidence of habit formation at the level of annual frequency in food consumption data from the US Panel Study on Income Dynamics.

Earlier we noted that another route for modelling aspirations would be to suppose that household felicity depends not only on its current consumption level, but also on the current rate of change in consumption. It could then be that household aspirations remain unfulfilled when the growth rate of consumption declines at a rate that cancels the felicity gain from increased consumption. We do not know of any empirical work along that line of enquiry. ${ }^{15}$

Although leisure is also a consumption good, it can be that certain forms of leisure are not publicly observable. We have shown that if consumption is conspicuous but leisure is not, people consume more and work harder in a market economy than they would at a social optimum (Proposition 2). However, if leisure is conspicuous as well, matters are different. We have identified the class of felicity functions for which conspicuous consumption and leisure lead to no distortion (Proposition 3). That finding allowed us to identify classes of felicity functions for which conspicuous consumption and leisure amount to people consuming and working more than they would at a social optimum and classes for which the effect amounts to people consuming and working less than they would at a social optimum. But the intuition that conspicuous consumption inevitably leads to a form of the problem of the commons is mistaken.

\footnotetext{
${ }^{15}$ Chakravarty and Manne (1968) studied the limiting case where felicity depends only on the rate of change in consumption $(\mathrm{d} C(t) / \mathrm{d} t)$.
} 


\section{Appendix}

In the body of this paper it was assumed that there is a single capital asset. In fact Propositions 1-3 hold under more general production structures. Here we offer an outline of the required analysis. For simplicity, we revert to the case of a single consumption good. As in Section 1, labour is assumed to be supplied inelastically. $U(c, C)$ is the felicity function of the representative household, satisfying condition (2a-b).

There are $N$ capital assets $(i, j=1, \ldots, N)$. Let $K^{i}(t)$ denote its stock at $t$. We assume that $K^{1}$ has two special properties: it is an input in its own production and, as in the single capital-good model, $C$ is a subtraction from its accumulation. In addition to the $N$ capital assets, there are a number of economic instruments (control variables), which may be subject to atemporal restrictions. To illustrate, imagine that asset $i$ is allocated to the production of other assets. If $K^{i j}(t)$ is the quantity of $i$ allocated to the production of $j$ at time $t$, then the corresponding restriction to the allocation would be

$$
\Sigma_{j} K^{i j}(t) \leq K^{i}(t)
$$

$K^{i j}(t)$ is a control variable at $t$, which is subject to restriction (60).

Exhaustible and renewable natural resources can also be included on our list of assets. For an exhaustible resource the restriction would be that the total quantity extracted and used in the production of various investments (including the extraction process itself) equals the rate at which the resource is depleted.

Let $\underline{v}(t)$ be the vectors of instruments at $t$ and let $\underline{K}^{j}(t)$, where $\left.\underline{K}^{j}(t)=\left(K^{1 j}, \ldots, K^{N j}\right)\right)$, be the vector of capital assets allocated to the production of investment in asset $j$. The general formulation of production can then be represented by a vector differential equation,

$$
\begin{aligned}
\mathrm{d} K^{1}(t) / \mathrm{d} t & =F^{1}\left(\underline{K}^{1}(t), \underline{v}(t), t\right)-C(t), \\
\mathrm{d} K^{i}(t) / \mathrm{d} t & =F^{i}\left(\underline{K}^{i}(t), \underline{v}(t), t\right), \quad i=2, \ldots, N
\end{aligned}
$$


and two sets of atemporal restrictions, namely (60) and $M$ constraints $(k=1, \ldots, \mathrm{M})$,

$$
g^{k}(\underline{v}(t)) \geq 0, \quad \text { for } k=1, \ldots, M .
$$

We suppose that, for all $i, F^{i}$ is concave and that, for all $k, g^{k}$ in (63) is a concave function.

We now prove Proposition 1 for this production structure.

Let $p^{i}(t)$ be the shadow price of the $i$ th asset. Then the current-value Hamiltonian is,

$$
H(t)=U(c(t), C(t))+\Sigma_{i} p^{i}(t) F^{i}\left(\underline{K}^{i}(t), \underline{v}(t), t\right)-p^{1}(t) c(t) .
$$

Given the $N$-vector $\underline{K}(t), \underline{v}(t)$ is determined by maximizing $H(t)$ - equivalently, $\Sigma_{i}$ $p^{i}(t) F^{i}\left(\underline{K}^{i}(t), \underline{v}(t), t\right)$ - with respect to $\underline{K}^{i}(t)$ for each $i$ and $\underline{v}(t)$, subject to the atemporal constraints (60) and (63). In order to do that, we can define the Lagrangean,

$$
L(\underline{K}, \underline{v}, t)=\Sigma_{i} p^{i}(t) F^{i}\left(\underline{K}^{i}(t), \underline{v}(t), t\right)+\Sigma_{i} w^{i}\left(K^{i}(t)-\Sigma_{j} K^{i j}(t)\right)+\Sigma_{k} \lambda^{k} g^{k}(\underline{v}(t)),
$$

where $\underline{w}$ and $\underline{\lambda}$ are non-negative Lagrange multipliers associated with constraints (60) and (63), respectively.

The multipliers $\underline{w}$ and $\underline{\lambda}$ are obtained from the first order conditions and conditions (60) and (63), for given values of $\underline{p}$ and $\underline{K}$. Clearly, $\underline{w}$ is homogeneous of degree one in $\underline{p}$. Moreover, the equations of motion of $\underline{p}(t)$ are:

$$
\mathrm{d} p^{i}(t) / \mathrm{d} t=\delta p^{i}(t)-\partial L(t) / \partial K^{i}(t), \quad i=1, \ldots, N .
$$

From (66) it follows that

$$
\left[\mathrm{d} p^{1}(t) / \mathrm{d} t\right] / p^{1}(t)=\delta-\partial F^{1}(t) / \partial K^{11}(t) .
$$

Notice that the right-hand side of equation (67) depends only on the paths of the state variables and the instruments.

The rest of the argument follows the one in Section 2. If the socially optimal and market equilibrium paths are the same, the right-hand side of equation (67) are identical for the two paths, so that equation (12) holds for $p^{1}(\mathrm{t})$. Moreover, using equation (16), we can confirm that (9) and (10) hold for $i=1$. This proves Proposition 1. Propositions 2 and 3 follow similarly. 


\section{References}

Ali Choudhary, M. and P. Levine (2006), "Idle Worship", Economic Letters, 90(1), 77-83.

Alvarez-Cuadrado, F. (2007), "Envy, Leisure, and Restrictions on Working Hours", Canadian Journal of Economics, 40(4), 1286-1310.

Bagwell, L.S. and B.D. Bernheim (1996), "Veblen Effects in the Theory of Conspicuous Consumption", American Economic Review, 86(2), 349-373.

Blanchflower, D. and A.J. Oswald (2004), "Well-Being Over Time in Britain and the USA", Journal of Public Economics, 88(7-8), 1359-1386.

Chakravarty, S. and A.S. Manne (1968), "Optimal Growth When the Instantaneous Utility Function Depends on the Rate of Change in Consumption", American Economic Review, 58(5), 1351-1354.

Charles, K.K., E. Hurst, and N. Roussanov (2007), "Conspicuous Consumption and Race", NBER Working Paper 13392, National Bureau of Economic Research, Cambridge, Massachsetts.

Clark, A.E., P. Frijters, and M.A. Shields (2008), "Relative Income, Happiness, and Utility: An Explanation for the Easterlin Paradox and Other Puzzles", Journal of Economic Literature, 46(1), 95-114.

Cooper, B., C. Garcia-Penalosa, and P. Funk (2001), "Status Effects and Negative Utility Growth," Economic Journal, 111(2), 642-665.

Duesenberry, J.S. (1949), Income, Saving, and the Theory of Consumer Behavior (Cambridge, MA: Harvard University Press).

Dynan, K.E. (2000), "Habit Formation in Consumer Preferences: Evidence from Panel Data", American Economic Review, 90(3), 391-406.

Easterlin, R. (1974), "Does Economic Growth Improve the Human Lot? Some Empirical Evidence", in P.A. David and M. Reder, eds., Nations and Households in Economic Growth: Essays in Honor of Moses Abramowitz (New York: Academic Press).

Easterlin, R. (1995), "Will Raising the Incomes of All Increase the Happiness of All?", Journal of Economic Behaviour and Organization, 47(1), 35-47.

Easterlin, R. (2001), "Income and Happiness: Toward a Unified Theory", Economic Journal, 111(3), 465-484

Frank, R. (1985a), Choosing the Right Pond: Human Behavior and the Quest for Status (New York: Oxford University Press). 
Frank, R. (1985b), "The Demand for Unobservable and Other Nonpositional Goods," American Economic Review, 75(1), 101-116.

Frey, B.S. and A. Stutzer (2002), "What Can Economists Learn from Happiness Research?", Journal of Economic Literature, 40(2), 402-435.

Howarth, R. (1996), "Status Effects and Environmental Externalities," Ecological Economics, 16(1), 25-34.

Ireland, N. (1994), "On Limiting the Market for Status Signals", Journal of Public Economics, 53(1), 91-110.

Kapteyn, A., P. Kooreman, P. Kuhn, and A.R. Soetevent (2007), "Measuring Social Interactions: Results from the Dutch Post Code Lottery", Discussion Paper, Department of Economics, Tilburg University.

Layard. R. (1980), "Human Satisfaction and Public Policy", Economic Journal, 90(4), 737-750.

Layard, R. (2005), Happiness: Lessons from a New Science (New York: Penguin).

Layard, R. (2006), "Happiness and Public Policy: A Challenge to the Profession", Economic Journal, 116, C24-C33.

Leibenstein, H. (1950), "Bandwagon, Snob, and Veblen Effects in the Theory of Consumers' Demand", Quarterly Journal of Economics, 64(1), 183-207.

Lucas, R.E. and N.L Stokey (1984), "Optimal Growth with Many Consumers", Journal of Economic Theory, 32(1), 139-171.

Luttmer, E.F. (2005), "Neighbors as Negatives: Relative Earnings and Well-Being", Quarterly Journal of Economics, 120(3), 963-1002.

Maurer, J. and A. Meier (2008), "Smooth it Like the "Joneses"? Estimating Peer-Group Effects in Intertemporal Consumption Choice", Economic Journal, 118(527), 454-476.

Ng, Y.K. (1987), "Relative Income Effects and the Appropriate Level of Public Expenditure," Oxford Economic Papers, 39(2), 293-300.

Oswald, A.J. (1997), "Happiness and Economic Performance", Economic Journal, 107(Features), 1815-1831.

Ryder, H.E. and G.M. Heal (1973), "Optimal Growth with Intertemporally Dependent Preferences", Review of Economic Studies, 40(1), 1-31.

Schor, J. (1998), The Overspent American (New York: Basic Books). 
Stokey, N.L. and R.E. Lucas - with E.C. Prescott - (1989), Recursive Methods in Economic Dynamics (Cambridge, MA: Harvard University Press).

Veblen, T. (1925), The Theory of the Leisure Class: An Economic Study of Institutions (London: George Allen \& Unwin). 